\title{
Impact of Covid-19 pandemic on Asia-Europe relations
}

\section{Lay Hwee Yeo ${ }^{1}$}

Published online: 19 May 2020

C) Springer-Verlag GmbH Germany, part of Springer Nature 2020

We are facing an unprecedented challenge of containing the coronavirus, the fear and uncertainty that it is spreading and the catastrophic economic consequences of the lockdown measures taken by many nations. How we respond to these challenges will shape the future not only of our individual societies and nations but also the wider regional and global order. In the absence of US leadership, what can countries in Europe and Asia and regional organisations like the European Union (EU) and the Association of Southeast Asian Nations (ASEAN) do to rebuild trust and institutions ravaged by the coronavirus? What will be the impact of Covid-19 on the connectivity agenda between Asia and Europe? Are we heading towards de-globalisation and what will be the future of Asia-Europe relations and the respective platforms such as the Asia-Europe Meeting (ASEM) that connect them?

\section{From China to the world-the cost of initial missteps}

From the time the coronavirus first appeared in Wuhan, China, in November 2019 to the WHO's declaration of Covid-19 as a global pandemic on 11 March, there were a series of missteps and missed opportunities. From China's initial cover-up of the extent of the human-to-human transmission of the coronavirus, to the lack of preparedness by many countries in responding to the pandemic, and the lack of concerted regional or global effort to address the threat - all these have added to the quandary the global community now faces - rising death toll, draconian measures to curb movement, and catastrophic economic consequences.

When the outbreak happened in Wuhan, many countries thought that it was enough to shut the borders from people arriving from Wuhan or China. Italy was the very first

Dr. Yeo Lay Hwee is Director of the European Union Centre at the Nanyang Technological University. She also holds Adjunct positions at the S Rajaratnam School of International Studies and the Singapore Management University, and is a Council Member of the Singapore Institute of International Affairs.

Lay Hwee Yeo

layhwee.yeo@ntu.edu.sg

1 EU Centre, Singapore, Singapore 
country in Europe to do so. Many countries in the West seemed to think that the virus could be stopped this way, and that it would be largely contained within East Asia as was SARS in 2003. They probably forgot that the world in 2019/2020 is very much different from 2003. In 2003, the Chinese economy was then the 6th largest economy and only $4 \%$ of global GDP. Chinese tourists made only 20.2 million overseas trips. By 2020 , China is the 2nd largest economy accounting for $17 \%$ of global GDP, and in the year 2018, Chinese tourists accounted for 149.7 million trips. The disruption to trade and supply chains when Wuhan and some other parts of China went on lockdown was palpable. The economic consequences of Covid-19 as it spreads and more and more countries went into lockdown have been catastrophic. The IMF has predicted that the world will enter into a deep recession in 2020 - something never seen before since the 1930s depression.

Countries across Asia and Europe are now scrambling to find an exit strategy from the lockdown to re-starting the economy and bringing life to a certain level of normalcy. Moving beyond the initial missteps and some of the testy discourse over who to blame, the world really needs to come together to look for an answer: how to jumpstart the global economy? More cooperation is also needed in the race to find a cure or vaccine. However, with the lack of US leadership and Trump's blame game, and the lack of trust in Chinese leadership, a global response may not be in sight. What we can hope for is perhaps a patchwork of more pragmatic regional and inter-regional responses that will serve as stepping stones towards rebuilding trust and transparency and rethinking of our trade links, supply chains, and inter-connectivity. Specifically, for countries in Asia and Europe, there are the following platforms that should be considered in the cooperation against Covid-19.

\section{The EU-ASEAN inter-regional dialogue}

When the coronavirus spread from China to other parts of Asia and Europe, the nationalistic response to shut borders and ban exports of medical equipment were painfully in full display. Particularly in the European Union, where the free flow of goods, services, capital, and people were held up as cardinal principles, the unilateral shutdown of borders and export bans were unprecedented, to say the least. The principles underlying the functioning of the Single Market collapsed as EU member states rushed to hoard medical supplies and imposed stringent lockdowns, closing borders and even airspaces. Nationalistic instincts kicked in and trumped all the talks about solidarity. Aggressive economic nationalism that undermines the Single Market was the initial response, leading the President of the European Commission, Ursula von der Leyen, to lament that "a crisis without borders cannot be solved by putting barriers between us".

In Asia, each country also approached the challenge in its own way. It also did not pull together a regional response. Even in the sub-region of Southeast Asia where there is ASEAN, multilateral cooperation came to a standstill as countries responded without much coordination casting doubts on the several response mechanisms that ASEAN has supposedly put in place to respond to pandemics and public health emergencies. Yet all is not lost. During the ASEAN foreign ministers meeting on 9 April 2020, 
several collective steps to fight the pandemic, including the establishment of a Covid19 response fund, were agreed upon.

As the two regional organisations stepped up their roles to coordinate and support their respective member states to fight Covid-19, information sharing and experiences can also be exchanged at the inter-regional platform.

The EU and ASEAN have been planning for some time now to upgrade their partnership to one with a strategic purpose. Addressing this global pandemic and preparing for future public health crisis should be a good starting point. The more important mission that they have to remember is probably to keep linkages open between different regions.

\section{ASEM}

In an article in ThinkChina, Chinese academic Yu Zhi argued that China should selfreflect and embark on a path of gaining genuine goodwill from the international community by apologizing for its part in the pandemic; and when extending help to others, China should not think it is doing others a favour or being a saviour.

It would be farfetched to expect China to apologise for the handling of Covid-19. However, there is much China can do to regain the trust of its partners, particularly in Europe. ASEM, which brings together 51 nations from Asia and Europe, and the EU and ASEAN, is a perfect platform for a real dialogue that can prevent an emerging narrative that is being purveyed in the West of China as a problem. It would be a real tragedy if at a time when countries need to come together to address various challenges there would be further polarisation and a hardening of positions dividing China and the West.

The next ASEM summit is to be hosted by Cambodia in November 16-17 this year. Depending on how the battle against Covid-19 goes, the summit should go ahead online if not face to face. The Cambodian government has chosen the theme "Strengthening Multilateralism for Shared Growth" for the 13th summit. While the theme was decided before the coronavirus ravaged across the whole world, the need for Asia and Europe to coordinate a multilateral response to reviving the economies could not have been more pressing now.

Without a coordinated multilateral approach towards the reopening of the economies, and resuming normal trade and investment flows, countries may face another wave of infections without a vaccine in sight. Increased connectivity between Asia and Europe should be maintained but we must also recognised that such connectivity comes with risks that need to be managed. Hence, it should not be surprising too that after Covid-19, there will be demands for greater diversification of supply chains and changes to national and regional stockpile policies for essential resources, to build greater resilience. Asia and Europe should continue to build links and create more networks of trade, people, and commerce. However, countries and regions will also have to put in place circuit breakers and backup systems, and there is much that Asia and Europe could also share information and experience on these using the ASEM platform.

ASEM could also be a platform for synergizing the different connectivity agendas of its members - from the ASEAN Masterplan on Connectivity to the Chinese Belt and Road Initiative (BRI) to the latest EU-Japan Partnership on Connectivity. Learning 
from the disruptions caused by Covid-19 means prioritising sustainability and resilience of the different connectivity plans and projects.

\section{Conclusion}

The blame game and the battle of narratives that is unfolding between the US and China over Covid-19 will distract us from the real work that needs to be done if the global community is to emerge out of this pandemic stronger and ready for future battles against global challenges of such scale as the Covid-19 or climate change. Over the last weeks, the Europeans have also been drawn into this battle of narratives.

Before more damage is done, and views and borders harden between China and the West, it is in the interest of countries in Southeast Asia and its regional organisation, ASEAN, to step up its inter-regional dialogue with Europe, through the EU, to prevent the fragmentation of the world in closed blocs. The ASEM platform also provides the sliver of hope that China will not be problematized, and can be an additional forum for dialogue and cooperation between Asia and Europe. 